\title{
Effects of Heel-insole on Static Balance and Postural Strategy during External Perturbation in Healthy Young Men
}

\author{
Cheol-Jin Kang', Duck-won Oh², Sung Min Son ${ }^{2}$ \\ 'Department of Physical Therapy, Graduate School of Health Science, Cheongju University, Cheongju, Republic of Korea; ${ }^{2}$ Department of Physical \\ Therapy, College of Health Science, Cheongju University, Cheongju, Republic of Korea
}

Purpose: This study examined the effects of heel insoles on the static balance and leg muscle activity and posture control strategy during external perturbation.

Methods: Thirty healthy young men participated in the study. The subjects underwent two experimental conditions: 1) no heel insole condition $(0 \mathrm{~cm})$ and 2 ) wearing heel insole condition $(5 \mathrm{~cm})$. The static balance was measured using an I-Balance device, which measured the change in the center of gravity (COG). The onset time of muscle activation and muscle activation of the erector spinae (ES), hamstring (HAM), gastrocnemius (GCM) were measured using surface EMG electrodes to determine the change in posture control strategy during external perturbation.

Results: The speed and distance of COG were significantly higher in the wearing heel insoles condition than the no heel insole condition $(p<0.05)$. In addition, significant differences in the onset time of the GCM, HAM, and ES muscle activation were observed when there was no heel insole condition during external perturbation $(p<0.017)$. On the other hand, no significant differences in the onset time of muscle activation were observed between GCM and HAM when wearing the heel insole condition during external perturbation $(p<0.017)$. Moreover, muscle activation of the GCM was significantly higher in the wearing heel insoles condition than the no heel insole condition during external perturbation $(p<0.05)$.

Conclusion: These findings suggest that heel insoles may have disadvantages, and increased efforts are needed to maintain balance and change the posture control strategy during external perturbation.

Keywords: Heel insole, Balance, Posture control strategy

\section{서 론}

신발은 하지 보행에 자연스러운 동작을 이루게 하여 발의 기능을 보 완해주며, 지면으로부터 받는 충격을 흡수하여 발을 보호하고 부상 을 방지하는 역할을 한다. ${ }^{1}$ 신발은 현대인들의 사회생활과 밀접한 연 관이 있으며 기능적인 측면에 집중되어 왔으나, 최근에는 미용적인 측면이 강조되고 있다. ${ }^{2}$ 최근에는 남성들도 작은 키를 보상하기 위해 굽이 높은 신발을 사용하거나 운동화에 키 높이 깔창을 사용하는 남 성들이 증가하고 있다. ${ }^{3}$ 그러나 키 높이 깔창을 착용을 통해 나타나 는 보행 및 균형 변화에 대해서 중요하게 생각하지 않는다. ${ }^{4}$

Choi 등에 의하면 신발의 높은 굽으로 인하여 발목관절의 위치가 변하면 외부 동요 시 무게중심 이동 변화가 맨발에 비하여 2 배 정도 높아지고, 발바닥 굽힘의 증가는 체중의 분포를 앞으로 이동시키고

Received Jan 12, 2021 Revised Feb 03, 2021

Accepted Feb 04, 2021

Corresponding author Sung Min Son

E-mailssm0417@hanmail.net
발목관절뿐만 아니라 하지 및 척추의 관절 위치를 변화시킨다. ${ }^{6}$ 또한 발목 주변 근육의 길이 변화로 발바닥굽힘근의 수축이 증가되어 근 피로도를 증가시킨다고 보고하였다. 무게중심의 변화 및 근피로도 의 증가는 자세조절 능력을 감소시키며, 외적 동요 시 더 많은 동요가 일어난다.6.8이러한 자세조절 능력 감소는 발목관절 외 무릎관절 및 엉덩관절에서 보상작용을 일으킬 수 있다. 또한 높은 굽의 착용은 고 유수용성감각의 능력을 감소시키고, 체성감각에 변화가 일어날 수 있는데, ${ }^{10}$ Sambit Mohapatra 등1에 의하면 체성감각의 변화가 일어나 면 외부 동요 시 균형회복 능력이 감소되고 근 수축 개시시간이 늦어 진다고 하였다. 이러한 근골격계적, 감각계적 변화들은 낙상 위험도 를 높이게 된다. ${ }^{12}$

균형은 신체의 중심이 지지기저면(base of support) 범위 내에서 벗 어나지 않고 자세를 유지하는 능력이다. ${ }^{13}$ 인간은 일상생활 중 외부
Copylight (C)2021 The Korean Society of Physical Therapy

This is an Open Access article distribute under the terms of the Creative Commons Attribution Non-commercial License (https:// creativecommons.org/license/by-nc/4.o.) which permits unrestricted non-commercial use, distribution, and reproduction in any medium, provided the original work is properly cited. 
동요에 의하여 균형이 벗어나는 경험을 하는데, ${ }^{14}$ 외부의 충격으로 인 해 자세에 동요가 생기면 균형 회복을 위해 시각, 안뜰기관, 고유수용 성감각과 신경근의 반응 등 복합적인 기능이 필요하다..$^{5}$ 견고한 지지 면에서 적은 동요가 발생 시 발목관절 전략이 가장 먼저 나타나고 이 는 발목관절 근육이 먼저 수축한다. ${ }^{16}$ 발목관절 전략만으로 균형 유 지가 힘든 경우 엉덩관절 전략을 사용하며 이는 엉덩관절 근육이 먼 저 수축한다. ${ }^{17}$ 키 높이 깔창 착용은 신체 배열의 변화와 발목의 관절 가동범위, 근력, 위치감각 등의 변화를 일으킬 수 있는데, ${ }^{3}$ 신체의 감 각 및 운동 요소에 변화가 생기면 신체 동요 시 평형 유지 능력이 저 하되어 자세 동요 시 균형 회복을 위해 더 많은 근활성도를 필요로 하 고 자세조절 전략에 영향을 미친다고 보고하였다.12.18

이와 같이 남성들의 키 높이 깔창 착용은 자세조절 능력에 부정적 인 영향을 주는 요인으로 작용하고 있으며, 선행 연구에서도 정적 균 형과 동적 균형을 감소시킨다고 보고하였다.19 하지만, 이전 선행 연구 들은 키 높이 깔창 착용으로 인한 압력분포의 변화, 균형능력의 변화 를 측정하였으며, 외적 동요에 따른 근육의 활성도 및 근 수축 개시를 통한 자세조절 전략에 대한 연구는 부족한 실정이다. 따라서 본 연구 의 목적은 젊은 남성들을 대상으로 키 높이 깔창 사용에 따른 근활 성도 변화 및 근 수축 개시시간을 통한 자세조절 전략의 변화를 확인 하며, 추가적으로 다양한 조건에서 정적 균형능력을 확인하였다.

\section{연구 방법}

\section{1. 연구 대상자}

본 연구의 대상자는 20 대 남성 30 명으로 최근 6 개월 동안 신경학적, 정형외과적 문제가 있는 자, 6 개월 이전 발목의 상해를 경험한 자, 현 재 신체 전반적인 불편감이나 통증을 호소하는 자, 그리고 정신과적 문제가 있는 자는 연구에서 제외시켰다. 모든 대상자들은 본 연구의 내용을 이해하고 참여할 것을 서면 동의하였다. 연구 대상자의 평균 나이는 $22.2 \pm 0.8$ 세이었으며, 평균 신장은 $172.9 \pm 10.5 \mathrm{~cm}$ 이었고, 평균 체중은 $69.3 \pm 14.5 \mathrm{~kg}$ 이었으며 우세측 다리는 오른쪽이 24 명 $(80 \%)$, 왼 쪽이 6 명 $(20 \%)$ 이었다.

\section{2. 실험방법}

\section{1) 키 높이 깔창}

키 높이 깔창은 시중에서 쉽게 구할 수 있는 높이 $5 \mathrm{~cm}$ 인 깔창이며 실 리콘 재질로 발뒤꿈치를 지지하여 키를 높여준다. 장기간 사용하더 라도 불편하지 않으며 모든 신발에 탈부착이 가능하다.

\section{2) 균형 능력 평가 장치}

균형능력 검사를 위해 균형능력 평가장치 I-Balance (Cybermedic Co,
Korea)를 이용하였다. 이 장치는 4 개의 로드셀이 장착된 힘판(force plate)을 이용해 신체동요에 따른 중력중심(center of gravity, COG)의 변화를 측정한다. 중력중심 이동에 따른 속도와 이동된 거리가 장비 관련 소프트웨어에 자동적으로 계산되며, 속도와 이동된 거리의 값 이 클수록 대상자의 자세동요가 많았음을 의미한다.

\section{3) 근전도 측정 및 자료 처리}

신체 동요 시 균형 회복을 위한 자세조절 전략을 검사하기 위하여 우 세측 다리의 근육들에 근전도를 측정을 시행하였다. 우세측 다리를 결정하기 위하여 대상자들에게 발로 공을 차도록 하였으며, 공을 차 는 다리를 우세측 다리로 결정하였다. ${ }^{20}$ 근전도 측정은 근전도 시스템 (Telemyo 2400T, Noraxon, USA)을 사용하여 우세측 다리의 안쪽장딴 지근(medial gastrocnemius), 뒤넙다리근(hamstrings), 척추세움근 (elector spine muscle)에 전극을 부착하였다. 전극은 안쪽장딴지근은 무릎관절 안쪽위관절융기와 발꿈치뼈(calcaneus)를 연결한 선의 상 위 $35 \%$ 부위에, 뒤넙다리근은 궁둥뼈 결절로부터 $15 \mathrm{~cm}$ 아래쪽 넙다 리두갈래근 중 내측에, 척추기립근은 L2 가시돌기로부터 가쪽 $2 \mathrm{~cm}$ 지점에 부착하였고, ${ }^{21}$ 근전도 신호의 차단 주파수(band width)는 20$450 \mathrm{~Hz}$ 사이로 설정하였으며, 근전도 신호에 표본 추출률(sampling rate)은 $1,500 \mathrm{~Hz}$ 로 하였다. 노치 필터(notch filter)는 $50 \mathrm{~Hz}$ 를 사용하였 다. 근육에서 평가된 근활성도 신호는 제곱평균제곱근(root mean square) 값으로 처리되었다. 근 수축 개시시간은 안정된 상태에 있을 때의 표준편차의 2 배 범위를 넘어섰을 때 근수축이 시작된 것으로 정 의하였다. ${ }^{22}$ 근전도 측정은 3 회 측정한 후 평균값을 이용하였다. 각 근 육들의 최대 수의적 등척성 수축 시 근활성도를 측정하기 위하여 맨 손근력검사 자세에서 측정되었다. ${ }^{23}$ 최대 수의적 등척성 수축(maximal voluntary isometric contraction, MVIC)의 평균 제곱근 값에 대한 백분율로 표준화하였다(\%MVIC). 최대 수의적 등척성 수축 평가는 1 분의 휴식 간격을 두고 2 회 시행되었으며, 그 평균값으로 계산되어 사용되었다.

\section{3. 실험 절차}

1) 정적 균형능력 검사(balance test)

균형능력 평가를 위해 기존 자신 자신이 착용하는 신발과 뒤굽이 5 $\mathrm{cm}$ 인 깔창을 착용 후 각각 검사하였다. 대상자는 균형능력 평가장치 I-Balance 위에 올라가 어깨 넓이로 발을 벌리고 양손은 가슴 위에 교 차한 자세로 측정되었다. 검사는 무작위 순서로 안정된 지지면과 스 펀지를 올려둔 불안정한 지지면 2종류 형태로 측정하였으며, 눈을 뜬 상태와 눈을 감은 상태로 각각 3 번씩 10 초 간격으로 중력중심의 변 화를 측정하였다. 네가지 조건에서 중력중심의 변화속도와 이동거리 의 평균값을 사용하였다. 
2) 외적 동요 시 근활성도, 근 수축 개시시간 검사

평가를 위해 기존 자신이 착용하는 신발과 뒤굽이 $5 \mathrm{~cm}$ 인 깔창을 착 용 후 각각 검사하였다. 모든 측정은 각 참가자들에게 동일하게 동요 판(perturbation board)에 중앙에 올라가서 어깨 넓이로 발을 벌린 후 팔은 정면 가슴 위에 $\mathrm{X}$ 자로 교차하고, 동요를 예측하지 못하게 시선 은 앞쪽에 핸드폰 영상을 바라보게 하였다. 동요는 동요판의 앞쪽으 로 유발하였고, 약 $4.0 \mathrm{~kg}$ 모래주머니를 줄을 이용하여 매달았다. 모 래 주머니 위치는 높이가 $90 \mathrm{~cm}$ 인 현수장치와 수직으로 위치하도록 길이를 조정하였다. 모래주머니를 수직 높이까지 전진, 후진시키고 1-10초 사이에 무작위로 낙하시켜 진자 운동력을 일정하게 제공하여 동요를 발생시켰다(Figure 1). 동요 시 낙상에 대비하기 위해 실험보조 자가 동요판 옆에 위치하여 보조하였다. 근전도 전극은 평가 전에 미 리 부착하였으며, 대상자가 외적 동요 시 균형을 유지하는 동안 나타 나는 우세측 다리의 장딴지근, 뒤넙다리근, 척추세움근의 근활성도 와 근 수축 개시시간을 측정하였다. 실험은 굽이 없는 신발과 $5 \mathrm{~cm}$ 깔 창을 무작위 순서로 착용한 후 측정하였다. 무작위 결정을 위해 $0 \mathrm{~cm}$ 와 $5 \mathrm{~cm}$ 가 쓰여 진 카드를 뒤집어 놓았으며 대상자들이 각각 카드를 뽑게 하였다. 동요의 발생 위치는 앞쪽으로 결정하였다. 각 조건에서 3 번씩 측정되었다. 측정에 따른 영향을 배제하기 위해 측정 간 대상자 에게 약 1 분 휴식을 취하였다.

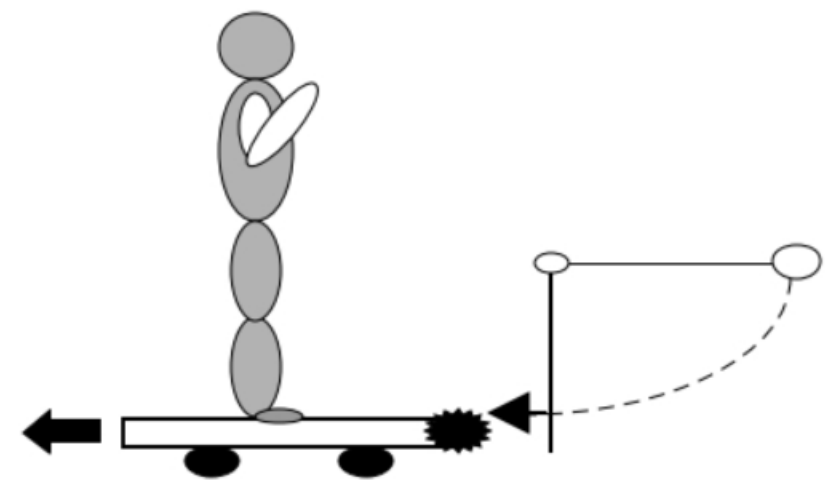

Figure 1. Perturbation device.

\section{4. 자료분석}

수정된 측정값들은 윈도우용 SPSS ver. 24.0 (Statistical Package for Social Science, Chicago IL, USA)를 사용하였다. 정규성 검정을 위해 콜모 고로프-스미노프검정(Kolmogorov-Smirnov test)을 실시하였다. $0 \mathrm{~cm}$ 와 $5 \mathrm{~cm}$ 깔창 조건 따른 근활성도, 중력중심의 동요속도 및 이동거리 를 비교하기 위해 대응표본 T검정(paired T-test)을 사용하였다. 통계 적 유의수준은 $\mathrm{p}<0.05$ 로 설정하였다. 신체동요 동안 $0 \mathrm{~cm}$ 조건과 5 $\mathrm{cm}$ 깔창 조건에서 각각 장딴지근, 뒤넙다리근, 척추기립근의 근 수축 개시시간에 차이가 있는지 비교하기 위해 크루스컬 윌리스(Kruskal wallis test) 비모수 검정을 실시하였다. 통계적 유의수준은 $\mathrm{p}<0.05$ 로 설정하였다. 유의한 차이가 있는 경우 근육간의 유의한 차이를 보기 위해 만휘트니(Mann Whitney test) 분석을 사용하였고, 통계적 유의 수준은 본페로니 보정(Bonferroni correction)을 이용하여 $\mathrm{p}<0.017$ 로 설정하였다.

\section{결 과}

\section{1. 깔창 미착용 $0 \mathrm{~cm}$ 조건과 $5 \mathrm{~cm}$ 깔창 착용 조건에서 평균 중력중심 동요속도, 이동거리 비교}

단단한 지지면에서 눈을 뜬 조건, 단단한 지지면에서 눈을 감은 조건, 불안정한 지지면에서 눈을 뜬 조건, 불안정한 지지면에서 눈을 감은 조건 모두 깔창 미착용 $0 \mathrm{~cm}$ 조건보다 $5 \mathrm{~cm}$ 깔창 착용 조건에서 평균 중력중심 동요속도, 이동거리가 유의하게 증가하였다 $(\mathrm{p}<0.05)($ Table 1).

\section{2. 깔창 미착용 $0 \mathrm{~cm}$ 조건과 $5 \mathrm{~cm}$ 깔창 착용 조건에서 동요 발생 시 각 근육들 간의 근 수축 개시시간의 비교}

동요발생 시 깔창을 착용하지 않은 $0 \mathrm{~cm}$ 조건과 인솔을 착용한 $5 \mathrm{~cm}$ 조건에서 모두 세 근육 간 근 수축 개시시간에서 유의한 차이가 나타 났다 $(\mathrm{p}<0.05)$ (Table 2). 사후 검정 결과, 깔창을 착용하지 않은 $0 \mathrm{~cm}$ 조 건에서는 장딴지근과 뒤넙다리근, 장딴지근과 척추기립근, 뒤넙다리

Table 1. The comparison of mean COG sway velocity, total distance between the condition

\begin{tabular}{|c|c|c|c|c|}
\hline & Condition & $0 \mathrm{~cm}$ & $5 \mathrm{~cm}$ & $t(p)$ \\
\hline \multirow[t]{4}{*}{ Velocity (Unit: m/s) } & Firm-Eyes open & $52.93 \pm 11.03$ & $103.36 \pm 21.55$ & $-3.852(0.001)^{*}$ \\
\hline & Firm-Eyes close & $73.45 \pm 15.31$ & $150.90 \pm 31.46$ & $-5.534(0.001)^{*}$ \\
\hline & Form -Eyes open & $67.31 \pm 14.03$ & $160.81 \pm 33.53$ & $-3.274(0.003)^{*}$ \\
\hline & Form-Eyes close & $94.61 \pm 19.72$ & $163.72 \pm 34.13$ & $-4.569(0.001)^{*}$ \\
\hline \multirow[t]{4}{*}{ Distance (Unit: mm) } & Firm-Eyes open & $263.75 \pm 51.81$ & $379.83 \pm 149.99$ & $-3.852(0.001)^{*}$ \\
\hline & Firm-Eyes close & $314.70 \pm 74.61$ & $419.54 \pm 109.66$ & $-5.385(0.001)^{*}$ \\
\hline & Form -Eyes open & $330.62 \pm 66.15$ & $435.66 \pm 159.90$ & $-3.244(0.004)^{*}$ \\
\hline & Form-Eyes close & $487.66 \pm 92.57$ & $593.26 \pm 205.08$ & $-2.701(0.013)^{*}$ \\
\hline
\end{tabular}

$\mathrm{M} \pm \mathrm{SD}$ : mean \pm standard deviation, $0 \mathrm{~cm}$ : no heel insole condition, $5 \mathrm{~cm}$ : wearing heel insole condition. ${ }^{*} p<0.05$. 
Table 2. The comparison of muscle activation onset time during external purturbation

(Unit: ms)

\begin{tabular}{lcc}
\hline & $0 \mathrm{~cm}$ & $5 \mathrm{~cm}$ \\
\hline GCM & $0.27 \pm 0.08$ & $0.39 \pm 0.03$ \\
HAM & $0.33 \pm 0.07$ & $0.34 \pm 0.07$ \\
ES & $0.41 \pm 0.08$ & $0.52 \pm 0.04$ \\
$p$ & $0.001^{*}$ & $0.001^{*}$ \\
\hline
\end{tabular}

M \pm SD: mean \pm standard deviation, GCM: Gastrocnemius, HAM: Hamstring, ES: Eretor spinae, $0 \mathrm{~cm}$ : no heel insole condition, $5 \mathrm{~cm}$ : wearing heel insole condition. ${ }^{*} p<0.05$.
Table 4. The comparison of muscle activation between the condition during external purturbation (unit: \%MVIC)

\begin{tabular}{lcrc}
\hline & $0 \mathrm{~cm}$ & $5 \mathrm{~cm}$ & $\mathrm{t}(\mathrm{p})$ \\
\hline GCM & $18.07 \pm 1.75$ & $22.31 \pm 1.95$ & $-3.496(0.002)^{*}$ \\
HAM & $8.34 \pm 0.86$ & $9.55 \pm 0.96$ & $-1.945(0.062)$ \\
ES & $15.38 \pm 1.51$ & $16.59 \pm 1.89$ & $-1.237(0.226)$ \\
\hline
\end{tabular}

$\mathrm{M} \pm \mathrm{SD}$ : mean \pm standard deviation, GCM: Gastrocnemius, HAM: Hamstring, ES: Eretor spinae, $0 \mathrm{~cm}$ : no heel insole condition, $5 \mathrm{~cm}$ : wearing heel insole condition. ${ }^{*} p<0.05$

Table 3. The comparison of muscle activation onset time during external purtubation

\begin{tabular}{|c|c|c|c|c|c|c|}
\hline & \multicolumn{3}{|c|}{$0 \mathrm{~cm}$} & \multicolumn{3}{|c|}{$5 \mathrm{~cm}$} \\
\hline & Mean Rank & Z & $\mathrm{p}$ & Mean Rank & Z & $p$ \\
\hline GCM-HAM & $24.17-34.83$ & -2.403 & $0.016^{*}$ & $27.28-31.72$ & -1.003 & 0.316 \\
\hline GCM-ES & $19.48-39.52$ & -4.518 & $0.001^{*}$ & $19.41-39.59$ & -4.549 & $0.001^{*}$ \\
\hline HAM-ES & $22.71-36.29$ & -3.064 & $0.002^{*}$ & $20.97-38.03$ & -3.849 & $0.001^{*}$ \\
\hline
\end{tabular}

$\mathrm{M} \pm$ SD: mean \pm standard deviation, GCM: Gastrocnemius, HAM: Hamstring, ES: Eretor spinae, $0 \mathrm{~cm}$ : no heel insole condition, $5 \mathrm{~cm}$ : wearing heel insole condition. ${ }^{*} p<0.017$

근과 척추세움근 사이에서 유의한 차이가 나타났다( $\mathrm{p}<0.017)$. 깔창 을 착용한 $5 \mathrm{~cm}$ 조건에서의 사후 검정 결과, 장딴지근과 뒤넙다리근 사이에서 유의한 차이가 나타나지 않았고 $(\mathrm{p}>0.017)$, 장딴지근과 척추 세움근, 뒤넙다리근과 척추세움근 사이에서 유의한 차이가 나타났 다 $(\mathrm{p}<0.017)($ Table 3$)$.

\section{3. 깔창 미착용 $0 \mathrm{~cm}$ 조건과 $5 \mathrm{~cm}$ 깔창 착용 조건에서 동요발생 시 근활성도의 비교}

동요발생 시 깔창을 착용한 조건과 착용하지 않은 조건에서 근활성 도가 장딴지근에서 유의한 차이가 나타났다 $(\mathrm{p}<0.05)$. 그러나 동요발 생 시 깔창을 착용한 조건과 착용하지 않은 조건에서 뒤넙다리근, 척 추세움근 근활성도는 유의한 차이를 보이지 않았다( $\mathrm{p}>0.05)$ (Table 4).

\section{고 찰}

본 연구는 젊은 남성들을 대상으로 키 높이 깔창 사용 시 균형조절 능력의 변화와 외적 동요 발생에 따른 자세조절 전략에 미치는 영향 을 알아보기 위해 정적 균형능력, 근활성도와 근 수축 개시시간을 확 인하였다. 본 연구 결과에서 키 높이 깔창 사용시 중력중심의 이동속 도와 중력중심의 이동거리에서 모두 유의한 증가가 나타났으며, 이는 키 높이 깔창 사용이 균형 조절 능력에 부정적인 영향을 주는 요소 로서 작용할 수 있음을 나타낸다. 또한 본 연구는 키 높이 깔창 사용 에 따라 외적 동요 발생시 자세조절 전략의 변화를 알아보기 위해 장 딴지근, 뒤넙다리근, 척추세움근의 근활성도와 근 수축 개시시간을 측정하였다. 근활성도의 변화는 장딴지근에서 키 높이 깔창 착용 후
유의하게 증가하는 것으로 나타났다. 또한 키 높이 깔창을 착용하지 않았을 때 각 근육사이 근 수축 개시시간은 유의한 차이를 보였으며, 근 수축 순서는 장딴지근, 뒤넙다리근, 척추세움근 순서로 나타났다. 키 높이 깔창을 사용하였을 때에도 세 근육 사이에서 근 수축 개시 시간에서는 유의한 차이가 나타났지만, 사후 검정 결과 장딴지근과 뒤넙다리근 사이의 근 수축 개시시간은 유의한 차이가 없었으며, 이 는 발목관절 전략과 엉덩관절 전략이 동시에 발생해 나타난 결과라 생각할 수 있다. 이러한 결과들은 키 높이 깔창의 착용으로 신체의 관절, 근육길이와 같은 변화로 인해 균형능력 및 자세조절 전략 변화 에 영향을 끼친 것으로 추정된다.

본 연구에서 정적 균형능력을 평가 하기 위해 균형능력 평가 장치 위에서 각 조건에 따라서 중력중심의 이동거리 및 이동속도를 비교 하였다. 실험결과 깔창을 착용하였을 때 거리 및 속도가 증가하였으 며, 이는 깔창 착용으로 인하여 균형능력에 영향을 준다는 것을 알 수 있다. 균형능력은 직립, 보행, 또한 스포츠활동 등 일상생활을 수행 하기 위해 중요한 신체능력이다. ${ }^{24}$ 균형을 유지하기 위해서는 시각, 평 형감각, 고유수용성감각 정보, 근골격계의 지지 작용 등의 요소들이 필요하다. ${ }^{17}$ 그러나 키 높이 깔창의 착용은 발목관절의 정상 위치를 변화시켜 발목의 가동범위, 두점 식별감각 능력 및 위치감각을 변화 시켜 균형능력을 감소시킨다고 하였다. ${ }^{3}$ Song 등 ${ }^{19}$ 의 연구에서도 20 대 남성의 키 높이 깔창을 착용은 균형능력을 감소시킨다고 하였다. 또한 신체중심점의 상대적인 상승은 직립 시 신체 안정성을 감소시 킨다고 하였다. ${ }^{25}$ 본 연구에서도 $5 \mathrm{~cm}$ 키 높이 깔창을 착용함으로써 신체중심점의 상승으로 균형능력에 부정적인 영향을 준 것으로 생 각되어진다. 이러한 결과는 일상생활 동안 키 높이 깔창의 착용은 잠 
재적으로 부정적인 영향을 줄수 있을 것이다.

중추신경계는 균형 회복을 위해 효율적인 전략을 사용하는데, ${ }^{26}$ 적은 동요가 있을 때 발목관절 주변 근육이 가장 먼저 수축하는 발 목관절 전략이 사용되며, 신체 운동, 감각에 문제가 발생하면 엉덩관 절 전략이 나타난다. ${ }^{27} \mathrm{Wilson}$ 등 28 은 발목관절의 각도가 변화되면 힘 의 생성이 늦어지고 힘도 감소함에 따라 발목의 기능이 저하되어 엉 덩관절의 보상작용이 일어난다고 보고하였으며, Røgind 등 29 은 발목 관절의 저운동성은 발목관절 전략을 감소시키고 엉덩관절 전략을 증가시킨다고 보고하였다. 또한 고유수용성감각 및 체성감각의 저하 는 자세조절 전략에 영향을 미칠 수 있다고 하였다. ${ }^{27}$ 본 연구 결과 외 적 동요 시 키 높이 깔창을 착용하였을 때 장딴지근의 근 수축 개시 시간이 느려지는 경향을 보이면서 뒤넙다리근과의 근 수축 개시시간 이 유의한 차이를 보이지 않았으며, 결과적으로 발목관절 전략과 엉 덩관절 전략을 동시에 사용하였다. 이러한 결과는 키 높이 깔창 착용 이 발목관절의 각도와 고유수용성감각 및 체성감각를 변화시키고 관절가동범위를 제한하여 엉덩관절 전략이 증가한 것으로 생각되 며, 발목관절의 기능 저하로 인한 엉덩관절과 체간근육의 보상작용 은 중추신경계의 효율적인 균형반응을 제한시킬 것이다. ${ }^{30}$ 이와 유사 하게 Sagong과 $\mathrm{An}^{31}$ 은 높은 굽의 신발을 착용하였을 때 불안정한 지 지면에서 발목관절 전략보다 엉덩관전 전략의 사용이 증가한다고 보 고하였다.

외적 동요 시 균형을 회복하는 동안 측정된 근활성도의 결과는 키 높이 깔창 착용 후에 장딴지근의 근활성도가 유의하게 증가하였다. 이러한 결과는 Son 등 32 의 높은 굽의 신발을 신고 자세를 유지하였을 때, 발바닥굽힘근의 활성도가 증가되었다는 선행연구와 비슷한 결과 이며, 키 높이 깔창과 유사하게 여성들의 하이힐 착용 후 서있을 때 장딴지근의 근활성도가 증가한다고 하였다. ${ }^{33}$ 키 높이 깔창의 착용으 로 인하여 뒤굽의 높이가 증가하면 발목관절의 발바닥굽힘의 증가 되고 상체의 무게 중심점은 앞으로 이동하며, 하체는 뒤쪽으로 이동 하는 운동학적, 동력학적 변화가 일어난다.6 이러한 변화는 발목관절 뿐만 아니라 하지 관절 전체에 부정적인 영향을 미친다. ${ }^{34}$ 발바닥굽힘 의 증가는 발등굽힘근의 이완을 유발하여 근활성도를 감소시키고, 반대로 발바닥굽힘근의 근활성도는 증가시킨다. ${ }^{32}$ 이와 같은 근활성 도의 변화는 키 높이 깔창 착용으로 인한 발바닥굽힘 상태의 변화에 대한 신체 역학적인 적응으로 설명될 수 있다. ${ }^{32}$ 이러한 본 연구의 결 과는 균형을 유지하기 위해 지속적인 근육 활성화가 요구되어 근 피 로를 증가시킬 가능성이 있으며, 일상생활에 부정적인 영향을 예측 하는데 도움이 될 것이다.

최근 남성들 또한 자신의 외모를 돋보이게 하고 신장이 커 보이게 하고자 키 높이 깔창을 착용하는 모습을 쉽게 볼 수 있다.35 하지만 키 높이 깔창은 신체 배열을 변화시키며, 발목의 가동범위, 고유수용성
감각, 균형능력 감소 등 부정적인 영향을 끼친다. 본 연구 또한 키 높 이 깔창 착용이 균형능력을 감소시키고 외적 동요로 인하여 균형 회 복 시 엉덩관절 전략의 사용이 증가하였으며 발목관절 주변 근육의 근활성도가 증가하였다.

이러한 결과는 키 높이 깔창이 발목관절의 불안정해질 가능성이 높아지고, 근골격계 상해 및 낙상 위험을 증가시키는 요인으로 작용 할 수 있음을 뒷받침 해준다. 본 연구의 결과 해석에는 몇 가지 제한 점을 가지고 있다. 첫째, 본 연구는 젊은 남성들을 대상으로 근전도 및 균형능력을 평가하였기 때문에, 모든 연령의 사람들에게 일반화 시켜 해석하기에 제한점이 있다. 둘째, 깔창의 재질과 형태 및 높이를 다양하게 설정하지 못하였다. 셋째, 장딴지근, 뒤넙다리근, 척추세움 근의 근 수축 개시시간 및 근활성도를 측정하기 위하여 표면 근전도 를 사용하였다. 측정 시 근육 주변 연부조직의 간섭신호가 포함될 가 능성이 있다. 넷째, 동일한 높이와 무게로 수직 낙하를 통하여 외적 동요를 유발하였지만, 정량화된 수치가 아니라 외적 동요의 힘의 차 이가 있을 가능성이 있다. 향후 연구는 이러한 제한점을 보완하여 여 러 측면에서 깔창의 착용시 변화에 대한 연구가 필요할 것이다.

\section{REFERENCES}

1. DeLisa JA, Gans BM, Walsn NE. Physical medicine and rehabilitation: Principle and Practice. 2nd ed. Pliladelphia, Lippincott Williams and Wilkins, 1993:168-9.

2. Lee KH, Kim YG, Hwang CM et al. Comparison of lumbar lordosis according to heel height in normal adults and patients with spondylolisthesis. J Korea Acad Rehabil Med. 2000;24(6):1186-90.

3. Jung JH, Kim JE, Moon YY et al. The effect of height increase elevator shoes on whole body functional changes. Korean J Sports Sci. 2009;18 (2):1403-18.

4. Menz HB, Lord SR. Footwear and postural stability in older people. J Am Podiatr Med Assoc. 1999;89(7):346-57.

5. Choi HK, Cho WH. The Effects of high-heeled posture on COP kinematics and muscle fatigue during the balance control of human body. Key Eng Mater. 2006;321:1119-22.

6. Snow RE, Williams KR. High heeled shoes: the effect on center of mass position, posture, three-dimensional kinematics, rear foot motion, and ground reaction forces. Arch Phys Med Rehabil. 1994;75(5):568-76.

7. Ebbeling CJ, Hamill J, Crussemeyer JA. Lower extremity mechanics and energy cost of walking in high-heeled shoes. J Orthop Sports Phys Ther. 1994;19(4):190-6.

8. Corbeil P, Blouin JS, Bein F et al. Pertubation of the postural control system induced by muscular fatigue. Gait Posture 2003;18(2):92-100.

9. Kerrigan DC, Todd MK, Riley PO. Knee osteoarthritis and high-heeled shose. Lancet. 1998;351(9113):1399-401.

10. Gribble PA, Hertel J, Denegar CR et al. The effects of fatigue and chronic ankle instability on dynamic postural control. J Athl Train. 2004;39(4): 321-9.

11. Mohapatra S, Krishnan V, Alexander S. Postural control in response to 
an external pertubation : effect of altered proprioceptive information. Exp Brain Res. 2012;217(2):197-208.

12. Lee JH, Kim K. Effect of heel-heights of shoe on balance in older women. J Korea Sport Res. 2007;18(2):311-30.

13. Horak FB, Nashner LM. Central programming of postural movement: adaptation to altered support-surface configuration. J Neurophysiol. 1986;55(6):1369-81.

14. Sun D, Gu Y, Mei Q et al. Effect of heel heights on female postural control during standing on a dynamic support surface with sinusoidal oscillations. J Mot Behav. 2016;48(2):19-46.

15. Desai A, Goodman V, Kapadia N et al. Relationship between dynadic balance measures and functional performance in community-dwelling elderly people. Phys Ther. 2010;90(5):748-60.

16. Granacher U, Roth R, Muehlbauer T et al. Effects of new unstable sandal construction on measures of postural control and muscle activity in women. Swiss Med Wkly. 2011;141:w13182.

17. Runge CF, Shupert CL, Horak FB et al. Ankle and hip postural strategies defined by joint torques. Gait Posture. 1999;10(2):161-70.

18. Mauritz KH, Dietz V. Characteristics of postural insability induced by ischemic blocking of leg afferents. Exp Brain Res. 1980;38:117-9.

19. Song GC, Park MJ, Jo SY et al. Effects of shose Insole height on static and dynamic balance among healthy young men. KSIM. 2015;3(3):49-57.

20. Edwards L, Dixon J, Kent JR et al. Effect of shoe heel height on vastus medialis and vastus lateralis electromyographic activity during sit to stand. J Orthop Surg. 2008;3(1):2.

21. Cram JR, Kasman GS, Holtz J. Introduction to Surface Electromyography. Maryland, Aspen Publishers Inc, 1998:153-5.

22. Hislop H, Daniels MJ. Worthingham's muscle testing. 8th ed. Philadelphia, Elsevier, 2007:102-3

23. Hodges PW, Bui BH. A comparison of computer based methods for the determination of onset of muscle contraction using electromyography. Electroencephalogr Clin Neurophysiol. 1996;101(6):511-9.
24. Johnson BL, Nelson JK. Practical Measurements for Evaluation in Physical Education. 4th ed. New York, MacMillan, 1986:236.

25. Jonkera I, Stewart C, Spaepen A. The complementary role of the plantarflexors, amstrings and gluteus maximus in the control of stance limb stability during gait. Gait Posutre. 2003;17:264-72.

26. Almedia GL, Carvalho RL, Tails VL. Postural strategy to keep balance on the seesaw. Gait Posture. 2006;23(1):17-21.

27. Speers RA, Kuo AD, Horak FB. Contributions of altered sensation and feedback responses to changes in coordination of postural control due to aging. Gait Posure. 2002;16(1):20-30.

28. Wilson EL, Madigan ML, Davidson BS et al. Postural strategy changes with fatigue of the lumbar extensor muscles. Gait Posture. 2006;23(3): 348-54.

29. Røgind H, Lykkegaard JJ, Bliddal $\mathrm{H}$ et al. Postural sway in normal subjects aged 20-70year. Clin Physiol Funct lmaging. 2003;23(3):171-6.

30. Kim HR, Kim HJ, Lee JW et al. The Effect of adjusted balance training and muslce training on balance using ankle strategy. PNF and Movement. 2014;12(3):133-42.

31. Sagong WW, An DH. Postural strategy by the difference of shoe heel height during quiet standing on an unstable surface. Phys Ther Korea. 2014;21(2):28-36.

32. Son JS, Choi HS, Hwang SJ et al. Changes of muscle length and roll-over characteristics during hig h-heel walking. J Korean Soc Precis Eng. 2007; 24(12):29-35.

33. Oh DW, Chon SC, Shim JH. Effect of shoe heel height on standing balance and muslce activation of ankle Joint. J Ergon Soc Korea. 2010;29(5): 789-95.

34. Lee CM, Jeong EH, Freivalds A. Biomechanical effects of wearing highheeled shoes. Int J Ind Ergon. 2001;28(6):321-6.

35. Cho JH, Kim RB. The effect of raised heel Insole on patellofemoral compressive force during walking. J Sport Leis Stud. 2012;50(2):935-44. 